\title{
College Students' Perceptions of Influenza Vaccination and Childhood Immunizations
}

\author{
Samantha E. Czyz ${ }^{1}$, Janelle Y. Miller ${ }^{1}$, Hope M. Muniz ${ }^{1}$, Samuel P. Abraham ${ }^{1} \&$ Deborah R. Gillum $^{1}$ \\ ${ }^{1}$ Bethel University School of Nursing, Mishawaka, Indiana \\ Correspondence: Samuel P. Abraham, Bethel University School of Nursing, 1001 Bethel Circle, Mishawaka, \\ Indiana, 46545. E-mail: samuel.abraham @ betheluniversity.edu
}

Received: May 7, 2019

doi:10.20849/ijsn.v4i2.582
Accepted: May 21, 2019

Online Published: May 24, 2019

URL: https://doi.org/10.20849/ijsn.v4i2.582

\begin{abstract}
Background: After reviewing the literature on flu vaccinations and childhood immunizations, it was concluded that participation in these preventative measures is beneficial to health in increasing the chances of protection from specific diseases. Further studies show that not all college students receive them or plan to have their prospective children vaccinated. Purpose: The purpose of this study was to determine college students' perception of influenza vaccination and childhood immunizations. Method: This was a quantitative, non-experimental study with a descriptive design using two open-ended questions to enhance data collection. A total of 120 college students were recruited to participate in this study. The research questions were: "What are college students' perceptions of influenza vaccination?" and "What are college students' perceptions of childhood immunizations?" The health belief model was used to guide the study. Results/Conclusion: Survey results showed that many students in a Christian college believe immunization is effective and plan to immunize their future children. However, a few students stated a desire to learn more about immunization.
\end{abstract}

Keywords: college students, perceptions, immunizations, influenza, childhood vaccinations

\section{Introduction}

The Center for Disease Control (CDC, 2017) recommends that everyone over six months of age should get an influenza vaccination annually unless there is a contraindication. Benefits of receiving the vaccination include avoiding hospitalization and avoiding absence from school and work. Childhood immunizations are also important. The members of the World Health Organization (WHO, 2018b) are focused on increasing vaccination rates worldwide to prevent diseases like polio, measles, and diphtheria. Not all college students get a flu shot annually (Rogers, Bhar, \& Benjamin, 2018) or want to vaccinate their future children (Espeleta, Beasley, Ridings, Smith, \& Shields, 2017). Understanding the views of college students may enable healthcare workers to provide effective teaching so that more people may take preventative health measures. The purpose of this study was to determine the perceptions of college students on influenza vaccination and childhood immunizations.

\subsection{Background}

Vaccinations are arguably one of the best ways to prevent disease. Immunizations are vital to decreasing the number of people who die from the disease (WHO, 2018a). Immunization benefits both the individual and the community. The CDC recommends that children get vaccinated and presents an immunization schedule to facilitate this (CDC, 2018). Espeleta et al. (2017) and Rogers et al. (2018) conducted studies to determine what factors prevent people from getting immunized. Albright and Allen (2018) studied how college students view the Human Papillomavirus (HPV) vaccination, but few have researched how college students view other types of immunization. There have been limited studies on the views of Christian college students. Education and promotion of vaccinations can improve with the knowledge of how college students perceive these immunizations.

\subsection{Research Questions}

There were two central research questions used in this study and two open-ended questions:

RQ1: What are college students' perceptions of influenza vaccination?

RQ2: What are college students' perceptions of childhood immunizations? 


\section{Review of the Literature}

Academic peer-reviewed journal articles were used in this literature review. Cumulative Index of Nursing and Applied Health Literature (CINAHL), Health Source, and EBSCO host were used to find and access articles using the keywords: college students, perceptions, immunizations, influenza, and childhood vaccinations. The selected articles were published from 2015 to 2018.

\subsection{Need for Vaccinations}

It has been indicated that childhood vaccinations are necessary and can prevent diseases such as polio, measles, and rubella. Individuals who are not vaccinated are more likely to present with preventable diseases (Jadhav, Winkler, \& Anderson, 2018). If enough people become immunized, an entire population could become immune to certain diseases (CDC, 2016).

Annual influenza vaccination is also beneficial. Influenza is a serious illness that could lead to death in vulnerable populations, such as children and the elderly (WHO, 2018c). College students are also considered a vulnerable group because living in close quarters facilitates the spread of the disease (Ratnapradipa, Norrenberns, Turner, \& Kunerth, 2017). Receiving annual flu vaccinations could help prevent a pandemic.

\subsection{College Students' Perception of Influenza Vaccination}

Healthcare professionals encourage annual influenza vaccination, and college students must decide whether to follow this recommendation. Ratnapradipa et al. (2017) found that college freshmen who had received a flu vaccination in previous years were more likely to get one when away from home. College freshmen vaccination decisions are heavily influenced by the views and behaviors of family members. Students who felt susceptible to influenza were more apt to get vaccinated, and the largest barrier to vaccination was side effects. College students may look to peers when making vaccination decisions. Ratnapradipa et al. concluded that most students were aware of peers receiving the influenza vaccination.

Huang et al. (2018) found that vaccination rates increase when student leaders reach out to peers during dormitory flu clinics. This outreach is considered a cost-effective way to promote health among young adults. Education may impact vaccination decisions. Kamimura et al. (2017) found having knowledge about influenza and vaccination prevents college students from viewing influenza vaccines negatively. Looper, George, Johnson, and Conway (2017) found most college students from a health science campus to be in favor of mandatory influenza vaccination policies. However, not all students with health-related majors view influenza vaccination positively. Rogers et al. (2018) found that $49.4 \%$ of undergraduate public health students who did not receive the flu vaccination believed that administration could cause the flu, and $30.4 \%$ were concerned about adverse side effects.

\subsection{College Students' Perception of Childhood Immunization}

College students are prospective parents and must eventually make decisions about childhood immunization. Espeleta et al. (2018) found that college students know which diseases vaccinations can prevent and usually view immunizations positively. Participants desired more research on immunizations and wanted them to be readily available without cost. Concerns included side effects, allergic reactions, and cost.

Many factors affect how college students view childhood vaccination. Jadhav et al. (2018) found the biggest perceived benefit was disease control, and the cost was reported as the most significant barrier. Personal experience with vaccination greatly impacted the views of college students, along with the opinions and experiences of close relatives. Perceived safety of vaccination also served as a major influencer.

\subsection{Mandatory Vaccination}

The debate has surrounded the idea of making vaccines mandatory. Parental autonomy and the welfare of society must be taken into consideration (Crossley, 2015). Studies have been conducted to better understand the views of college students and faculty. A mandatory vaccination program was implemented at the University of Pittsburgh for researchers and staff who worked with infectious microorganisms in the laboratory. Employees were educated about the vaccinations. A survey was conducted to determine if this education prompted laboratory workers to get vaccinated. Results indicated that most of the students and staff did not feel pressured into getting vaccinated but chose to do so willingly. The program was considered effective due to the inclusion of researchers and staff in its development and its educational component (Lang \& Stitt-Fischer, 2015).

Even when childhood vaccinations are considered mandatory, it is possible to obtain a waiver in some states. Jadhav et al. (2018) found college students with vaccination waivers perceive immunization differently than those who do not. A third of the students with waivers believed that childhood immunization could cause autism 
and did not plan on getting up to date on vaccination.

College students and faculty often have opinions on whether influenza vaccination should be required. Looper et al. (2017) studied the views of students and staff from a health science campus. A survey was conducted, and the majority of participants viewed mandatory influenza vaccination positively. However, faculty members would be more likely to get vaccinated than students if it was not mandatory. Factors such as cost and convenience may impact students, and further education concerning vaccination may be needed.

\subsection{Summary of the Literature Review}

Based on the reviewed literature, multiple studies have been conducted on influenza vaccination and childhood immunizations. Jadhav et al. (2018) emphasized the ability of childhood vaccination to prevent disease. College students' perception of influenza vaccination is significantly influenced by the beliefs of their family members and peers (Ratnapradipa et al., 2017). Study of college students' perceptions of childhood immunizations revealed concern about cost and side effects (Espeleta et al., 2018). Education has been shown to influence how college students perceive mandatory vaccinations (Lang \& Stitt-Fischer, 2015). A gap in research was found regarding Christian college students' understanding of vaccinations and immunizations. Therefore, additional research is needed to understand Christian college students' perception of influenza vaccination and childhood immunizations.

\subsection{Theoretical Framework}

The theoretical basis for this study was the health belief model (HBM). Rosenstock (1974) explained that the health belief model was made through a series of studies in the 1950s that were conducted by a group of behavioral scientists for the Public Health Service. These scientists suggest that all behavior in life is "being pulled by positive forces and repelled by negative forces" (Rosenstock, 1974, p. 329). Negative forces are most often considered disease or conditions. Positive forces are actions that prevent, stop, or alleviate the effects of negative forces. Hochbaum (1958) believes that people need to take part in public health programs to prevent disease and to detect it early. To understand why people, do or do not take part, the theory focuses on five factors: perceived susceptibility, perceived seriousness, perceived benefits, perceived barriers, and cue to action. These words are defined in the section on conceptual definitions. The HBM uses these factors to understand human behavior and adjust healthcare to fit the needs of recipients. Hochbaum described the influence of these factors as psychological preparedness. The basis of this model was used when creating all survey questions to receive insight of students' perceptions of seriousness, susceptibility, barriers, and benefits, and other factors and cues to action that influence if they choose to vaccinate or refuse. Conducting a study using the five factors helped guide understanding of student perceptions so that nursing professionals can adjust healthcare to fit the needs of this population.

\subsection{Definition of Terms}

\subsubsection{Operational Definition}

College students for this study were defined as students ranging from the age of 18 to 26 and are attending an institution of higher learning in northern Indiana, which is a Christian institution. Senior nursing students were excluded from this study. Influenza was defined as a contagious viral infection that attacks the respiratory system. Childhood immunizations were defined as vaccines that stimulate the immune system and help protect against infection or disease and included the immunizations recommended by the CDC. Perceptions were defined as the views, beliefs, and thoughts that an individual has on a topic.

\subsubsection{Conceptual Definition}

Rosenstock (1974) defined perceived susceptibility as the level of disease risk one believes oneself to have. Perceived seriousness is the importance, priority, or urgency that one places on an action or disease. Perceived benefit is the positive outcomes one would gain from an action. Perceived barriers are the situations, requirements, or indicators that impede one's participation in an action. Cue to action is anything that motivates one to an action. Psychologically prepared is when an individual is under the influence of the factors listed above (Hochbaum, 1958).

\section{Methodology}

\subsection{Method and Design Appropriateness}

This study was a quantitative, non-experimental study with a descriptive design using two open-ended questions to complement the results. A cross-sectional approach helped gather data at one point in time. Approval from the Institutional Review Board (IRB) was obtained before data collection. 


\subsection{Geographic Location and Sample}

This survey took place in early March by the entrance of the Dining Commons on the university campus. Permission was obtained from the manager of the Dining Commons. Convenience sampling was used where traditional freshman, sophomore, junior, and senior students, who are from the age of 18 to 26 were recruited to participate. All genders and ethnicities were recruited.

\subsection{Data Analysis Plan}

After the surveys were collected from participants, an analysis of demographic and survey items took place. While analyzing demographic data, percentage and frequency were calculated through nominal measurements. Standard deviation and mean were also calculated while analyzing survey questions. The mean and deviation were calculated through an ordinal scale by using a Likert-type scale. This data was organized into an excel spreadsheet for data analysis. The analyzation of this information provided a comparison of how data differed or concurred. Tables and figures were constructed to visually analyze and compare data findings.

\subsection{Survey Instrument}

The survey instrument included six demographic items, 22 quantitative survey items, and two open-ended survey questions. These items were constructed based on the research questions. Items 1-11 were based on RQ1: College students' perceptions of the influenza vaccination. Items 12-22 examined RQ2: College students' perceptions of childhood immunizations. A Likert-type six-point scale was used to assess participants' perception. The six-point scale ranges from 1 (Strongly disagree), 2 (Disagree), 3 (Somewhat disagree), 4 (Somewhat agree), 5 (Agree), and 6 (Strongly disagree). Identical survey instruments were distributed to all students.

\subsection{Instrument Reliability and Validity}

The survey tool was developed after a thorough review of the literature. A Likert-type six-point scale with constant numerical values was used to establish uniformity among results. The legitimacy of the survey tool was tested using face-validity (Schmidt \& Brown, 2019) when it was evaluated by two peers and two faculty members from the College School of Nursing

\subsection{Informed Consent and Confidentiality}

The researchers completed a training course from the National Institute of Health (NIH) Office of Extramural Research and received the "Protecting Human Research Participants" certificate. Participants took part in the study voluntary and had the right to withdraw at any time. Informed consents were given to the participants which described the purpose of this study. Participants signed and returned the form to the researchers before taking the survey. The signed consents and completed surveys were placed in separate manila envelopes. Participants received a copy of the informed consent that included contact information that could be used to ask questions.

All collected data for this research were submitted to College School of Nursing to be stored electronically for three years. College School of Nursing staff scanned the data into the computer and store it on discs in a locked cabinet in a locked storage room. None other than the nursing administrators or the research coordinators have access to the stored records.

\section{Results}

The literature review was used as a background for analyzing survey results. The HBM was utilized to understand the perceptions participants hold about vaccination. The purpose of this study was to determine college students' perceptions of influenza vaccination and childhood immunizations. Results show that most students view influenza vaccination and childhood immunization positively.

Participants signed consent forms before taking the survey. Only current college students 18 to 26 years of age were surveyed. Store bought candy was given as an incentive. Participants were informed that all names and responses were kept confidential. The consent forms and surveys were separated from each other due to the ability to identify a participant based on the signature. Incomplete surveys were discarded. After collection, data was organized into an excel spreadsheet.

\subsection{Demographic Characteristics}

Participants in this study were college students, ages 18 to 26 . One hundred and twenty students completed the survey. Table 1 displays the demographic characteristics of the participants. It includes gender, age, class, ethnicity, and whether vaccinations were received. 
Table 1. Descriptive statistics for participant demographics and background

\begin{tabular}{lll}
\hline Variable & f & \% \\
\hline Gender & 41 & 34.2 \\
\hline Male & 9 & 65.8 \\
\hline Age & 69 & \\
\hline $18-20$ & 50 & 57.5 \\
\hline $21-23$ & 1 & 41.7 \\
\hline $24-27$ & & 0.8 \\
\hline Class & 32 & \\
\hline Freshmen & 23 & 26.7 \\
\hline Sophomore & 42 & 19.2 \\
\hline Junior & 23 & 35.0 \\
\hline Senior & & 19.2 \\
\hline Race/Ethnicity & 91 & 75.8 \\
\hline White & 9 & 7.5 \\
\hline Hispanic or Latino & 14 & 11.7 \\
\hline Black or African American & 4 & 3.3 \\
\hline Asian & 1 & 0.8 \\
\hline Native American & 1 & 0.8 \\
\hline Other & 106 & 32.8 \\
\hline Received influenza vaccine in the past year & 67.5 \\
\hline Yes & 39 & 11.7 \\
\hline No & 81 & \\
\hline Received recommended vaccinations & \\
\hline Yes & 14 & \\
\hline No & & \\
\hline & 14.3 \\
\hline
\end{tabular}

Note: $\mathrm{N}=120$.

Various profiles were represented. Forty-one males (34.2\%) and 79 females (65.8\%) took the survey. Most students were age 18 to 20, with $69(57.5 \%)$ participating in the survey. Fifty students age 21 to 23 (41.7\%) participated in the survey. Only one $(0.8 \%)$ student age 24 to 27 participated in the survey. All classes were represented. Thirty-two (26.7\%) were freshmen. Twenty-three (19.2\%) were sophomores. Forty-two (35\%) were juniors, and $23(19.2 \%)$ were seniors. The racial/ethnic breakdown was 91 (75.8\%) White students, nine (7.5\%) Hispanic or Latino students, 14 (11.7\%) Black or African American students, four (3.3\%) Asian students, one $(0.8 \%)$ Native American student, and $1(0.8 \%)$ student from another ethnicity. Researchers found that 39 (32.5\%) of the participants received an influenza vaccine in the past year and $81(67.5 \%)$ had not. Results also revealed that $106(88.3 \%)$ of the participants received the recommended childhood immunizations and $14(11.7 \%)$ did not.

\subsection{Item Set Description}

Table 2. Student perceptions on influenza vaccination

\begin{tabular}{lll}
\hline Variable & M & SD \\
\hline 11. Influenza can be deadly in any person. & 4.83 & 1.17 \\
\hline 10. The flu is a serious infection. & 4.33 & 1.24 \\
\hline 1. Influenza (flu) vaccine protects me from getting the flu. & 4.23 & 1.42 \\
\hline
\end{tabular}




\begin{tabular}{lll}
\hline 9. I do not feel in danger of contracting the flu. & 4.22 & 1.30 \\
\hline 8. I feel knowledgeable about the influenza vaccine. & 4.10 & 1.39 \\
\hline 2. Influenza vaccine protects me against the different types of flu. & 3.93 & 1.37 \\
\hline 4. The cost of the vaccine keeps me from receiving the influenza vaccine. & 3.88 & 1.58 \\
\hline 7. The influenza vaccine gives me the flu. & 3.83 & 1.63 \\
\hline 6. Influenza vaccine should only be given to the elderly and children. & 2.71 & 1.44 \\
\hline 5. I do not receive the influenza vaccine unless it is required. & 2.34 & 1.11 \\
\hline 4. The cost of the vaccine keeps me from receiving the influenza vaccine. & 2.04 & 1.20 \\
\hline 3. My faith impacts my decision in receiving the influenza vaccine. & 1.98 & 1.23
\end{tabular}

Note: $\mathrm{N}=120$, Items were rated on a six-point Likert-type scale from 1 (Strongly Disagree) to 6 (Strongly Agree). Higher means indicated higher levels of agreement.

\subsubsection{Research Question One}

The first research question was, "What are college students' perceptions of influenza vaccination?" Survey items 1-11 addressed this question. Students rated their level of agreement based on a six-point Likert-scale (1) meaning strongly disagree, (2) meaning disagree, (3) meaning somewhat disagree, (4) meaning somewhat agree, (5) meaning agree, and (6) meaning agree. In Table 2, means $(M)$ are ranked from highest to lowest along with their corresponding standard deviations $(S D)$. The most common agreement among students was that influenza can be deadly to any person $(M=4.83, S D=1.17)$. Based on the mean, many students also agreed that influenza is a serious infection $(M=4.33, S D=1.24)$. Thirdly, a significant number of participants expressed agreement that the influenza vaccine does protect from the flu $(M=4.23, S D=1.42)$. However, many students agreed that they did not feel in danger of contracting influenza $(M=4.22, S D=1.40)$. Some students agree that they felt knowledgeable about the influenza vaccination $(M=4.10, S D=1.39)$.

\subsubsection{Research Question Two}

The second research question was, "What are college students' perceptions of childhood vaccination?" Items 12-22 related to childhood immunizations. A six-point Likert scale of "agreement" was used. Ratings were measured as (1) strongly disagree, (2) disagree, (3) somewhat disagree, (4) somewhat agree, (5) agree, and (6) strongly agree.

In Table 3, means were ranked from highest to lowest. Most students agreed that they would get their future children immunized $(M=5.14, S D=1.12)$. Next, many students agreed that childhood immunizations are effective in preventing disease $(M=4.95, S D=1.04)$.

A significant number of students agreed that childhood immunizations prevent illnesses that are serious $(M=4.88$, $S D=1.05)$. Based on the mean, many students agreed that childhood immunizations protect society $(M=4.83$, $S D=1.17)$. A comparable number of students also agreed that childhood immunizations should be given according to the schedule recommended by the $\mathrm{CDC}(M=4.83, S D=1.17)$.

Table 3. Student perceptions of childhood immunization

\begin{tabular}{lcc}
\hline Variable & Mean & SD \\
\hline 22. If I have children in the future, I will have them immunized. & 5.14 & 1.12 \\
\hline 13. Childhood immunizations prevent disease. & 4.95 & 1.04 \\
\hline 14. Many illnesses that childhood immunizations prevent are severe. & 4.88 & 1.05 \\
\hline 16. Childhood immunizations keep the rest of society safe from diseases. & 4.83 & 1.17 \\
\hline 12. Childhood immunizations should be given according to the recommended CDC schedule. & 4.83 & 1.17 \\
\hline 15. Society and the media encourage childhood immunizations. & 4.12 & 1.22 \\
\hline 20. All childhood immunizations are safe. & 3.95 & 1.22 \\
\hline 21. I am well informed about childhood immunizations. & 3.71 & 1.53 \\
\hline
\end{tabular}




\begin{tabular}{lcc}
\hline 17. Children receive more shots than needed. & 2.98 & 1.27 \\
\hline 18. Childhood immunizations have severe side effects. & 2.98 & 1.27 \\
\hline 19. Childhood immunizations cause autism. & 1.89 & 1.06 \\
\hline
\end{tabular}

Note. $(\mathrm{N}=120)$. Items were rated on a six-point Likert scale ranging from 1 (Strongly Disagree) to 6 (Strongly Agree). Higher means indicate higher levels of agreement.

\subsection{Discussion of Results}

The mean showed that most students perceive the flu to be a serious infection and see themselves at risk of contracting the flu. Many students perceived themselves to be knowledgeable of the flu vaccine. The majority perceived that the flu vaccine prevents one from contracting the flu. This data, however, was surprisingly not correspondent with the demographic data of students that received the flu vaccine in the past year. Only 39 of the 120 students stated to have received the vaccine in the past year. Eighty-one students stated that they had not received the flu vaccine in the past year. This data coincided with students' perception of "I do not feel in danger of contracting the flu." This data also corresponds with the HBM. Students who do not see themselves as susceptible did not act against contracting the flu. Faith was ranked lowest on influencing one's decision to obtain the flu vaccine.

Many students stated they would have their future children immunized. Students' perceptions favored the perceptions that the consequences of childhood diseases can be severe and that immunizations prevent these from occurring. There was also high agreeance that childhood immunizations keep society safe and should be given according to the CDC schedule. This data supports that students perceive the risk of childhood diseases and perceive disease control as a benefit of immunizations. Perceived benefit was ranked higher than perceptions of caused side effects and autism.

This data showed that most college students perceive the flu vaccine and childhood immunizations as positive benefits to society. Most students believed influenza and infectious diseases to be serious. Therefore, most were in favor of vaccination. Students perceived the benefits of immunizations to be greater than the perceived risk of not being immunized.

\subsubsection{What are College Students' Perceptions of Influenza Vaccination?}

This study concluded that students believe influenza can be deadly in anyone and that it is a serious illness. Many students did agree that the influenza vaccine protects them from the flu yet many of them did not feel in danger of contracting the illness. Lastly, many students agreed that they felt knowledgeable about the influenza vaccination. These results were not exactly congruent with the literature review (see Figure 1). Rogers et al. (2018) found that a significant number of students were concerned about the side effects of influenza vaccines. However, concern for the possible side effects of influenza vaccination was not a top theme in this study.

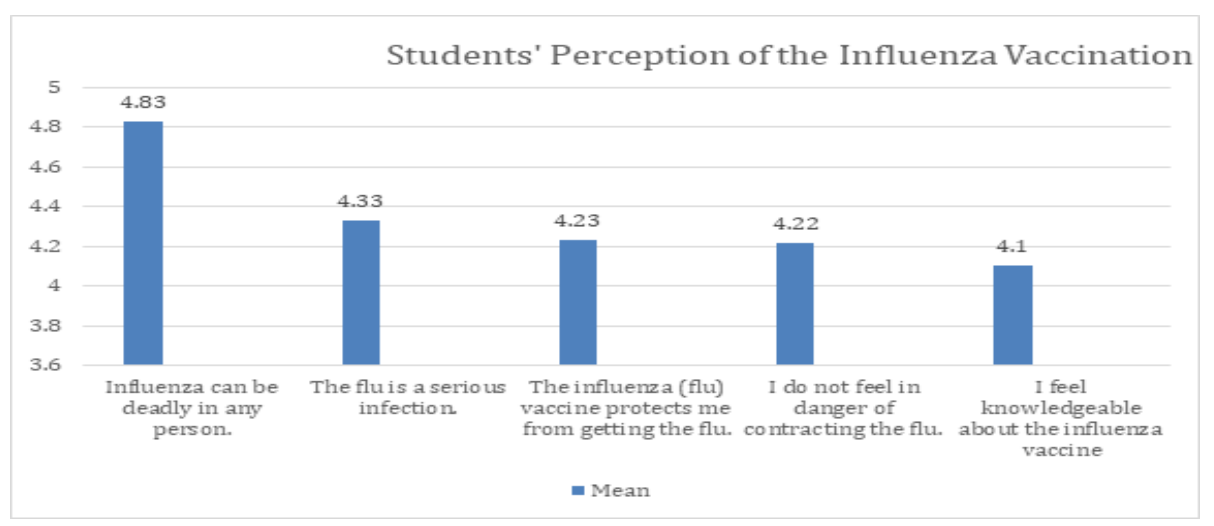

Figure 1. Student perceptions of influenza vaccination (mean scores on a 6-point Likert-type scale. N=120)

\subsubsection{What are College Students' Perceptions of Childhood Immunizations?}

The quantitative results of this study align with the literature review (see Figure 2). This study reveals that 
students agree that childhood immunization should be done and that they prevent disease. Students perceive that childhood immunizations prevent diseases that are serious and keep all of society safer. Jadhav et al. (2018) also found that many students believe immunizations prevent disease.

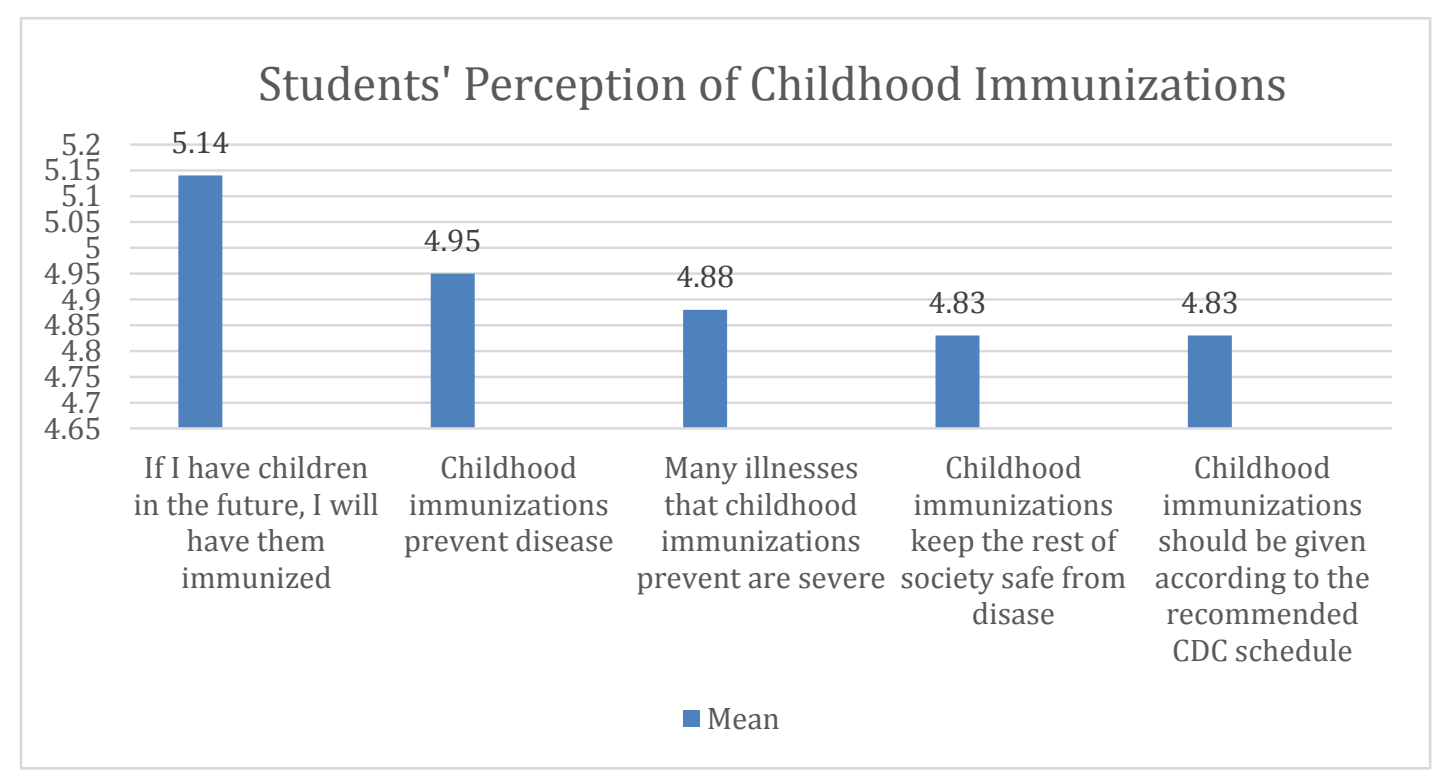

Figure 2. Student perceptions of childhood immunizations (mean scores on a 6-point Likert-type scale. $\mathrm{N}=120$ )

\section{Qualitative Analysis}

Qualitative themes were identified for both qualitative questions. Themes were first analyzed for the question, "What do you believe about the influenza vaccine?" Most students indicated that they believed influenza vaccines were "necessary" or that "everyone should get them." The second most prevalent theme was the idea that influenza vaccines are "not needed as much for some" or "sometimes necessary." This group of students was not totally for or against influenza vaccinations. Thirdly, several participants believed that influenza vaccines are "not necessary." This subgroup was against the vaccines and saw no value in them. Fourthly, some students stated that they did not feel knowledgeable about influenza vaccinations. Lastly, a few participants wrote about how they believed influenza vaccinations are effective against "some strains" of the illness.

The researchers next analyzed responses to the question, "What do you believe about childhood immunizations?" Most participants simply stated that childhood immunization was "necessary" or "important." The second most prevalent theme was the belief that childhood immunizations were important for children specifically. These participants did not necessarily believe that childhood immunization benefited all of society. However, the third most prevalent theme was the belief that childhood immunizations protect "everyone." Fourthly, some students wrote that childhood immunizations "do not cause autism." That comment was prevalent enough to be identified as a theme. Lastly, a few students indicated that they felt they have a "limited knowledge" of childhood immunization.

The researchers took the time to compare the qualitative themes with the quantitative themes and the literature review. A common theme was noted about the influenza vaccine when the results of the qualitative and quantitative questions were analyzed. Many college students consistently indicated the belief that the influenza vaccine effectively protects against influenza. A difference was noted between the qualitative and quantitative results. Many students agreed that they felt knowledgeable about the influenza vaccine in the quantitative portion. However, the statement that they did not feel knowledgeable was found to be the fourth most prevalent theme in the qualitative results. Overall, more students indicated that they did feel knowledgeable. The literature review about influenza vaccines closely coincides with the qualitative themes. Looper et al. (2017) found that students had mixed views on the influenza vaccine. Some viewed the vaccine positively while others viewed it negatively. The qualitative themes mirror those findings.

The qualitative and quantitative results of childhood immunization aligned closely. Students consistently indicated that they believe childhood immunization protects everyone in society and that administration prevents 
disease. In the qualitative study, the theme of students feeling that they had limited knowledge of childhood immunization was more evident.

The literature review about childhood immunization compared with the qualitative results. Espeleta et al. (2018) found that most students view childhood immunizations positively. This finding is consistent with the results of the qualitative study as most students stated that they believed childhood immunizations are important. Jadhav et al. (2018) found that students were concerned about the cost of immunizations. The qualitative study contrasts since no students mentioned cost.

\subsection{Limitations}

Limitations associated with this study included the location and time that the survey was conducted. Some students had little time to complete the survey. This may have led to incomplete surveys and vague statements. The Dining Commons is only open for a limited number of hours. Therefore, there were many students who could not take this survey. This study is also limited to surveying only one Christian college. It cannot account for all colleges and students across the United States. Other limitations to the study included those associated with the HBM. The model does not account for habitual actions that affect decision-making. The model also assumes that everyone has equal access to health information. While the HBM describes behavior well, it does not explain behavior. This makes the model helpful for understanding behavior, but not helpful for predicting behavior. Despite limitations, beneficial and useful data was collected.

\subsection{Clinical Implications}

This study is clinically relevant. It has the potential to help increase awareness of the educational needs of those most at risk for influenza and those who are potential parents. This study may also help emphasize the importance of influenza vaccination and childhood immunization. The survey allows increased knowledge of educational needs by showing the sample population's perceptions of the researched topics. Perceived importance of influenza vaccination and childhood immunizations may be understood through this survey by analyzation of specified survey questions. Through the qualitative question, the survey may show common themes among the specified population regarding influenza vaccination and childhood immunizations.

\subsection{Recommendations}

Further research would help to better understand how Christian college students view the influenza vaccine and childhood immunizations. It would be advantageous to use a larger sample to promote accuracy of results. It might also be important to study the views Christian college students hold on the HPV vaccine specifically, since religion may impact decisions on whether to receive it. Researchers should continue to compare the results of their studies with other findings to identify well-established themes.

\subsection{Conclusion}

In summary, this study provided insight into how Christian college students view influenza vaccination and childhood immunization. Since the CDC recommends vaccination, it is important to understand the perceptions of young people. Studying a subgroup of the young adult population contributed to a more thorough understanding of the topic. This study indicated that many students view vaccines positively, but some believed they need to learn more about them. Receiving further teaching may influence young people to take more preventative health measures in the future.

\section{References}

Albright, A. E., \& Allen, R. S. (2018). HPV misconceptions among college students: The role of health literacy. Journal of Community Health, 43(6), 1192-1200. https://doi.org/10.1007/s10900-018-0539-4

Center for Disease Control. (2016). Vaccines and immunizations. Center for Disease Control. Retrieved from https://www.cdc.gov/vaccines/terms/glossary.html

Center for Disease Control. (2018). Vaccines and immunizations. Center for Disease Control. Retrieved from https://www.cdc.gov/vaccines/index.html

Center for Diseases Control. (2017). For parents: Vaccines for your children. Center for Disease Control. Retrieved from https://www.cdc.gov/vaccines/parents/diseases/child/flu.html

Crossley, M. (2015). Including public health content in a bioethics and law course: Vaccine exemptions, tort liability, and public health. Journal of Law, Medicine \& Ethics, 43, 22-32. https://doi.org/10.1111/jlme.12263

Espeleta, H. C., Beasley, L. O., Ridings, L. E., Smith, T. J., \& Shields, J. D. (2017). Immunizing children: A 
qualitative analysis of future parental decision making. Clinical Pediatrics, 56(11), 1032-1039. https://doi.org/10.1177/0009922817701173

Hochbaum, G. M. (1958). Public participation in medical screening programs: A socio-psychological study. U.S. Department of Health, Education, and Welfare.

Huang, J. J., Francesconi, M., Cooper, M. H., Covello, A., Guo, M., \& Gharib, S. D. (2018). Community health workers on a college campus: Effects on influenza vaccination. Journal of American College Health, 66(4) 317-323. https://doi.org/10.1080/07448481.2018.1440582

Jadhav, E. D., Winkler, D. L., \& Anderson, B. S. (2018). Vaccination perceptions of college students: With and without vaccination waiver. Frontiers in Public Health, 6, 36. https://doi.org/10.3389/fpubh.2018.00036

Kamimura, A., Trinh, H. N., Weaver, S., Chernenko, A., Nourian, M. M., Assasnik, N., \& Nguyen, H. (2017). Knowledge and perceptions of influenza vaccinations among college students in Vietnam and the United States. Journal of Preventive Medicine and Public Health, 50(4), 268-273. https://doi.org/10.3961/jpmph.17.061

Lang, Y. C., \& Stitt-Fischer, M. (2015). Evaluation of a university-based mandatory vaccine program. Workplace Health \& Safety, 63(4), 179-188. https://doi.org/10.1177/2165079915580036

Looper, P., George, D., Johnson, E. J., \& Conway, S. E. (2017). Study and faculty perceptions about mandatory influenza vaccines on a health sciences campus. Journal of American College Health, 65(7), 513-517. https://doi.org/10.1080/07448481.2017.1341899

Ratnapradipa, K. L., Norrenberns, R., Turner, J. A., Kunerth, A. (2017). Freshman flu vaccination behavior and intention during a nonpandemic season. Society for Public Health Education, 18(5), 662-671. https://doi.org/10.1177/1524839917712731

Rogers, C. J., Bahr, K. O., \& Benjamin, S. M. (2018). Attitudes and barriers associated with seasonal influenza vaccination uptake among public health students: A cross-sectional study. BMC Public Health, 18(1). https://doi.org/10.1186/s12889-018-6041-1

Rosenstock, I. (1974). Historical origins of the health belief model. Health Education Monographs, 2(4), 328-335. https://doi.org/10.1177/109019817400200403

Schmidt, N. A. \& Brown, J. M. (2019). Evidence-Based practice for nurses: Appraisal and application of research. Burlington, MA: Jones \& Bartlett Learning, LLC.

World Health Organization. (2018a). Immunization coverage. World Health Organization. Retrieved from http://www.who.int/en/news-room/fact-sheets/detail/immunization-coverage

World Health Organization. (2018b). Immunization, vaccines and biologicals. World Health Organization. Retrieved from http://www.who.int/immunization/global_vaccine_action_plan/en/

World Health Organization. (2018c). Influenza. World Health Organization. Retrieved from http://www.who.int/en/news-room/fact-sheets/detail/influenza-(seasonal)

\section{Copyrights}

Copyright for this article is retained by the author(s), with first publication rights granted to the journal.

This is an open-access article distributed under the terms and conditions of the Creative Commons Attribution license (http://creativecommons.org/licenses/by/4.0/). 